\title{
Student Perceptions of Academic Librarians
}

\begin{abstract}
Questionnaire and interview techniques were used at the University of Nebraska at Omaha to study full-time student perceptions of the educational role of academic librarians. The results of the study emphasize the existence of vague, contradictory, and erroneous perceptions held about academic librarianship. Effective outreach programs and library services must be employed in the attempt to alter such views which not only affect relations between librarian and student but which also cause students to underutilize the librarian.
\end{abstract}

$S^{2}$ STUdies HAVE FOCUSED on faculty attitudes regarding librarian-faculty relationships and faculty lack of awareness about the services librarians offer. ${ }^{1} \mathrm{Li}$ brarians are often more aware of faculty than of student perceptions. In regard to student utilization of libraries, library literature reveals that the following points are repeatedly examined and/or questioned: (1) student assessment of their ability to use libraries; (2) how often and why students enter libraries; (3) what type of materials students utilize; and (4) whether students feel library use affects their

Peter Hernon is a doctoral student in the Graduate Library School, Indiana University, and was a reference librarian at the University of Nebraska at Omaha when the study was conducted. Maureen Pastine is a reference librarian at the University of Nebraska at Omaha. The authors express their gratitude to the following faculty members at the University of Nebraska at Omaha for their assistance: Clemm C. Kessler, Erwin H. Thormahlen, Rao Aluri, Sara Lou Williams, and John M. Christ. The Faculty Research Committee at the university provided financial assistance, and $D a$ vid $O$. Williams assisted with some of the statistical tests and their interpretation. scholastic achievement. This article presents a study of an area neglected by research: student perceptions about the roles, duties, and functions of academic librarians.

A 1963 study by Line is one of the more important surveys on perceptions, even though it has shortcomings. He stated that "There is a general impression that students use libraries far less than they ought to," and before librarians can change this they need to find out why. However, the study did not employ interviews due to "considerations of time and cost."2 The questionnaire did not explore perceptions with any great depth or accuracy. No differentiation was made between professional librarians and clerical help as both were grouped together under the term "library staff."

A 1971 survey of users of Brown University Library classified students who requested reference assistance by subject major. It was found that 46 percent of these users were humanities majors, although these majors comprised only 32 percent of the total student body. ${ }^{3}$ Swope and Katzer interviewed 119 persons using the Syracuse University library to determine if they had refer- 
ence questions. Of those who would not ask for reference assistance, most felt their questions were too elementary, were hesitant to disturb librarians, or had had an unsatisfactory previous experience in seeking assistance. ${ }^{4}$

Little has been done to discern the perceptions of nonusers. A nonuser may be defined as a person who spends two hours or less in the library per week and who uses it only for social, study-hall, or reserve reading purposes. Lubans' study of nonusers at Rensselaer Polytechnic Institute, although commonly cited as the major study of nonusers, assumes that students distinguish among library staff as to roles and duties. For example, students are asked: "Do you know any librarians?" A "major finding" is that library usage is primarily course-related, but such a conclusion is overly general. Course-related activities encompass reserve readings, study-hall, and research purposes. Lubans, however, makes a significant point:

Non-use has not been adequately treated in the literature nor has there been research in this area. Essentially, most studies of library users are based on people who happen to come into the library or are book borrowers. The studies concentrate on what the users do in the library, not how well, or for that matter for what purpose they use it, or how successful they are. Quite often the reports related the number of books borrowed versus the students' academic standing. ${ }^{5}$

The existing research reflects a lack of an in-depth discerning of student perceptions and conceptualizations of the role of academic librarians. Most studies of student use of libraries have included questionnaire items pertaining to perceptions toward librarians. However, these particular questions repeat the same points without describing those perceptions. One of the more commonly asked questions is "Have you ever consulted a librarian?" The expected re- sponse is either affirmative or negative. No further explanation of the response is required. It is assumed that students know who the librarians are, and there is no indication whether questions asked required professional assistance or were of a directional nature. Similar questions concentrate on how many times a librarian is asked a question, the correlation between familiarity with librarians and student willingness to ask questions, and the need for better rapport between librarians and the library staff.

\section{Statement of the Problem}

Librarians do not completely comprehend the nature and extent of student perceptions about them and their role in the educational process. With the trend toward independent study, outreach librarianship, and the application of psychology to reference desk service, precise knowledge of student perceptions and receptiveness to librarians is needed. The extent and types of misperceptions must be realized before the image of librarianship can be upgraded with regard to students.

The findings of the studies previously described illustrate the need for sophisticated research methodologies aimed at more than just actual library users. Surveys should not rehash the same points but seek a deeper understanding of basic student perceptions. ${ }^{6}$ Line sums up the need for in-depth research when he states:

... the use of attitude scales instead of rather crude categories is clearly desirable. Again, more satisfactory criteria of adequate or successful use of the library are required if librarians are to discover how far the barriers and difficulties they know to exist affect library use. A more sophisticated study could tell us much more about the library as the student sees it, and possibly help the librarian to see it with different eyes. ${ }^{7}$ 
With this in mind, the researchers' primary objective was to delineate and codify by type those perceptions as they were uncovered through this research project.

\section{Assumptions}

In order to acquire more information about student perceptions, the researchers studied the following research questions:

1. Do students perceive the role of librarians, clerical, or student assistants as being the same? The objective was to study the ability to distinguish among jobs.

2. Do students perceive librarians as service rather than teaching oriented? The researchers were interested in major accountabilities.

3. Do students believe that librarians do less than they actually do in terms of duties? The researchers were interested in an awareness and extent of job duties.

Each of these questions was examined by variables of age (those students thirty years old and younger and those over thirty), undergraduate class level, subject area (humanities, social sciences, and physical sciences), sex, student purpose for using the library and number of hours spent each week in using the library, and whether students received a library lecture conducted through the classroom or a library orientation.

\section{METHOD}

The sample for the study consisted of full-time students carrying at least twelve semester credit hours at the University of Nebraska at Omaha during the second semester of 1975. The University's Omaha Computing Facility personnel provided a computer program that randomly selected 700 names and addresses from current enrollment lists based on a proportionate percentage of names from each freshmen, sophomore, junior, senior, special, and graduate student file.
Two data collection devices were employed in the investigation: (1) questionnaire and (2) interview. The questionnaire contained thirty-eight multiple choice and short answer items. Interviews served as a cross check on the questionnaire findings, as interview questions were taken directly from the questionnaire. Beyond this, interview data are not presented in the results.

Questionnaire reliability was determined by using the test-retest procedure. The test and retest, separated by one week, were administered to a class of thirty upper division undergraduates. Analysis of the data using the Spearman Rank Order Correlation yielded a reliability coefficient of .897 . Interscore reliability, which is the percentage of coincidental item scoring by different scorers, was .910. The questionnaire, therefore, is reliable over time and can be scored consistently by independent scorers.

Validity was determined by investigating contrasted groups. Contrasted groups were used because it was expected that perceptions between librarians and student nonusers would be quite different. The researchers tested and found that there was indeed a difference. The Mann-Whitney U Test, which shows whether two independent groups were drawn from the same population, was used.

The questionnaire was given to ten university students who used the library less than two hours per week and to ten university librarians selected by a table of random numbers. Total scores were found to have a critical value of $U=$ 10. Critical values of $U$ for a one-tailed test are at $a=.001$. Therefore, the questionnaire distinguished between the two groups, where one would expect to find differences. This lends support to its ability to measure the characteristics which it was designed to measure.

In addition, interview findings were correlated with questionnaire responses. 
Twenty students randomly selected from those who returned the questionnaire were interviewed. Results are as follows for the Spearman Rank Order Correlation Coefficient: Students perceive librarians as service rather than teaching oriented $\left(\mathrm{r}^{2}=81.9\right.$ percent $)$, students believe that librarians do less than they really do in terms of duties $\left(r^{2}=91.3\right.$ percent $)$, and students perceive the role of librarians, clerical, or student assistants as being the same $\left(\mathrm{r}^{2}=\right.$ 86.5 percent). The statistics indicate an extremely high correlation and again confirm the quality of the survey instrument.

After testing and determination that it was of acceptable quality, questionnaires were mailed to the sample in March 1975 and accompanied with stamped self-addressed envelopes. One week later, students received postcards reminding them to return questionnaires.

\section{REsults}

Of the questionnaires mailed 51.7 percent (362) were returned. Chi square analysis shows that distributions under each class level are significantly different. Phi analysis indicates age and class level do not vary systemically together. Thus, in this return sample, some variable other than age was responsible for class assignment. This result is contradictory to what might be expected, and possibly the reason is that the sample was based on a proportionate percentage in each class and that juniors and seniors responded better than lower division undergraduates.

Data represent the views of users and nonusers, and they were found to have responded similarly. Twenty students were randomly selected from those who did not return questionnaires and twenty from those who did. They were interviewed, and the Mann-Whitney U Test was used to determine whether they were drawn from the same population.
Results indicate that there is no significant difference between the perceptions of both groups as to roles $(\mathrm{p}>.05)$, duties $(p>.05)$, and teaching-service orientation $(\mathrm{p}>.05)$.

Another forty of those not returning questionnaires were randomly selected and telephoned as to their reasons for not participating. They stressed that, as they did not use the library, librarians would neither be interested in their comments nor find them beneficial. These students lacked time to complete questionnaires because they held fulltime or part-time jobs while attending the university.

Nonusers who returned questionnaires were careful to point out their lack of need for the library but were still willing, in many cases, to express their opinions. One hundred and thirtyseven of the respondents (37.8 percent) answered the final item on the questionnaire, which invited additional comments. Of these seventy-seven (56.2 percent) were users, and sixty ( 43.8 percent) either did not use the library or used it for social, study-hall, or reserve reading purposes.

\section{Definition of Librarians}

Librarians were generally defined in terms of a reference function. As librarians are familiar with the library and its resources, they can assist students in finding needed sources. Only thirteen (3.6 percent) of the responses suggested a cataloging and organizational function and ten (2.8 percent) an acquisition role. Librarians were also viewed as library administrators and as individuals who work in a library. More often than not the librarian is "trained" or "skilled" rather than "educated" or "professional," or is seen as leading one to knowledge rather than imparting it. Other general comments suggested stereotype images and misperceptions. Librarians are "little old ladies behind a desk," check out or shelve books, file 
cards, and keep the library in order.

\section{Duties}

As for duties of reference librarians, students emphasized their role in locating needed information. Eighteen (5 percent) indicated collection building, but none suggested participation in instructional outreach programs. Suspected activities included, among others, managing the library, classifying and shelving books, and knowledge of their department. Mann-Whitney analysis indicates differences in the variables of sex $(p<.01)$, age $(p<.05)$, purpose for using the library $(p<.001)$, and having library classroom instruction ( $p$ $<.001$ ). Class level, however, was not significant.

\section{Professionalism}

Many students do not perceive librarians as having a special educational background and subject expertise. They assume that there are degree requirements for academic librarianship but are unsure of the specifics. Possibly they assumed requirements because of question phraseology. Still only eight (these were library users) realized that academic librarians have master's degrees in library science. It was perceived that librarians differ from student assistants and clerical help in educational background (87.1 percent, yes; 4.8 percent, no; 8.1 percent, unsure).

There is a relationship between whether students think librarians have subject specialties and whether they ask questions in the professional language of their subject field. To illustrate, 40.7 percent are unsure or do not think academic reference librarians have subject specialties whereas 69.5 percent "never" or only "sometimes" phrase queries in the language of the subject. However, 41.4 percent of the students suggested that librarians "frequently" or "always" have the same mastery of research methodology in subject areas as instructors.

\section{Roles}

The data indicate that libraries such as that at the University of Nebraska at Omaha have ineffective outreach programs and that many students feel that the educational role of the library is minimal or non-existent. Librarians were perceived as differing from student assistants and clerical help in roles for the variables of sex (p.0020), purpose for using the library $(p<.001)$, and having library instruction $(\mathrm{p}<.001)$, but not for class level (p.0869) and age (p.1151).

Student assistants were consulted primarily for four reasons: questions were of a directional or simple nature; student assistants were more available, friendly, or patient; they were personally known; and students preferred not to disturb busy librarians. Of the respondents, 23.7 percent had consulted student assistants while 12.6 percent did not know if they had.

Students were asked to explain how they knew if the person they consult is a librarian or another member of the library staff. Approximately 50 percent admitted that they "did not know" but assumed that librarians were older, sitting behind desks, more knowledgeable and competent in their assistance. Only forty-one students indicated that they would ask for a professional librarian if they needed expertise in problem solving in the library.

\section{Teaching-Service Orientation}

The verbal interchange between student and librarian is not necessarily conceived as a learning experience. Only 31.6 percent regard it as such an experience "frequently" or "always." With inclusion of the "sometimes" category, the amount is 86.6 percent.

Students generally did not think librarians should locate answers and ma- 
terials for them (22.5 percent, no; 59.4 percent, sometimes) but preferred librarians to educate them in finding the information for themselves ( 30 percent, frequently; 48.7 percent, always) and to suggest and explain other sources that will supply additional information. Only 11.6 percent frequently or always preferred their questions answered briefly and without any additional information.

Mann-Whitney analysis indicates that differences in the level of all variables, except class, had a significant influence on student perceptions of librarians as service or teaching oriented. Perceptions appear a function of student experiences with librarians. The variables of age, sex, purpose for using libraries, and having library instruction merit more analysis. With One Way Analysis of Variance, the subject areas were compared in relation to teaching-service orientation, roles, and duties. No significance was obtained. The variables operating to determine student perceptions of librarians within the various disciplines do not seem to differ significantly among the disciplines. The raw data upon which the statistical analysis was based show that 61.6 percent believed librarians perform a teaching function whereas 38.4 percent did not. No significance was found for the variables of sex, age, subject area, and class level.

\section{Interpersonal Relations}

Student willingness to request assistance was probed in the questionnaire. Only 16.1 percent "frequently" or "always" seek assistance immediately when searching for library materials and information in a library familiar to them. The rest generally prefer to attempt to locate materials without librarian assistance. All of the variables were analyzed, but none showed significant differences. Furthermore, whether or not students received a library lecture did not reduce their hesitancy to request assistance.

Students appreciate librarians leaving the reference desk and dealing with them on an individual basis (46.1 percent). The group (49.7 percent) expressing no preference, however, is misleading. Many indicated that it depends on the type of question and whether the librarian was busy. The reference desk itself was not perceived as a major barrier (70.1 percent, no; 20.1 percent, sometimes). Percentages are almost uniformly distributed by sex, class, and age.

In answer to a question concerning whether or not students were bothered by asking the same librarian for further assistance, 34.4 percent stated they were. Many students seemed to feel that librarians were understanding, responsive to their needs, and encouraged students to return if the need arose. Negative responses often came from students who pointed out general problems encountered in past experiences which made them hesitant to approach the same librarian twice. These problems included such factors as librarians showing impatience or annoyance when asked for assistance.

Another most often repeated comment was that the librarians seemed too busy and did not like to be bothered. Others felt foolish, embarrassed, shy, stupid, and a nuisance. Some felt that the problem was their own fault for not listening carefully the first time and thus did not think it fair to bother the same librarian a second time. Many pointed out that, to a great extent, it depended on the individual librarian, and his or her attitude during the first encounter. Some felt the librarian had not given complete assistance or paid careful attention the first time and probably would repeat this performance again.

\section{Library Lectures}

Instructional outreach programs can 
be considered from two perspectives: their impact on student research methodologies and on student perceptions toward librarians, their academic role and duties. The former consideration is beyond the scope of this study. As the Mann-Whitney analysis has shown, there is a perceptual difference between those who had and had not received library lectures. Of those answering this section of the questionnaire 70.3 percent felt that library lectures would be of value in meeting classroom and educational needs (26.6 percent, no; 3.1 percent, unsure). For many students, including those who had received lectures particularly geared to research methodology for their subject areas, lectures were still preferred primarily at the freshman level.

Of the students who had lectures 15.3 percent did not find them of value in meeting classroom and educational needs. They felt overwhelmed by the amount of material presented and were unsure of what to remember and how to translate the information into effective literature search strategies. Additionally, the lectured students were "bored" by extensive bibliographic presentations. Those not experiencing lectures and not thinking them of value suggested that the library was not important for their subject areas (i.e., business, chemistry, and art).

\section{Status of Librarians}

Librarians are concerned about their status, and the questions analyzed by the Two Way Analysis of Variance are particularly suited to investigate this area. The Two Way Analysis of Variance showed that response patterns among the three questions of roles, duties, and teaching-service orientation were essentially the same and that there were no significant differences among subject disciplines. Group perceptions did not differ with respect to any of the three research questions.
While overall the responses did not differ significantly, an analysis of interaction effects for specific questions does indicate some significant variation. For the question of duties, there was an interaction effect for the variables of sex $(p<.05)$ and class $(p<.05)$. Sex was significant for duties and roles $(p<$ .01 ) but not for teaching-service orientation $(\mathrm{p}>.08)$. Mann-Whitney analysis indicated that sex was significant for teaching-service orientation (p.0026). The difference in statistical accounts is probably explained by the fact that these scales assessed data from different perspectives; one considered an ordinal scale and the other an interval/ratio scale. Definitely, the unexpected and unexplained variable of sex merits further analysis.

\section{Analysis of Individual Questions by Users-Nonusers}

Questionnaires for fifty library users (library used at least two hours per week and primarily for research) and fifty nonusers (either not using the library or using it for social, study-hall, or reserve reading purposes) were randomly selected and individual questions compared by chi square to determine whether perceptions differed. Users and nonusers responded in the same way for all considerations except whether librarians were regarded as performing a teaching function ( $p<.05)$, and whether students ask queries in the professional language of a subject field $(p<.05)$.

\section{Discussion}

\section{The Three Research Questions Under Study}

Based on the results of the study, students generally confuse the functions and qualifications of library staff and perceive librarians as service oriented and as having less variety of duties than they actually have. The One and Two Way Analysis of Variance considered 
primarily status factors relating to the educational role and teaching activities of librarians. It may be hypothesized that if the factors of roles, duties, and teaching-service orientation are related to status, then librarians are low status people.

Perhaps librarians are not considered as teachers unless they are engaged in classroom activities or the verbal interchange in the reference room involves research related queries. Future studies need to probe student definitions of teaching as this study shows contradictory impressions. Many students stated that librarians had not played an important role in their college education and were not involved in an educational role. Yet some of these same students did consider the kind of activity reference librarians perform as teaching.

Users and nonusers do not differ in their understanding of librarianship, the nature of librarians' duties, educational background, and required literature search skills. They are interested in obtaining the answer to their queries and also in having librarians educate them to find information for themselves.

Students have difficulty in differentiating among library staff as to roles. Apparently as long as their needs are met, they are indifferent as to whether the person is actually a librarian. The vagueness of many replies underscores the lack of awareness of the roles and duties of librarians. On questions such as librarians' having subject specialties ( 59.3 percent, yes; 20.8 percent, no; 19.9 percent, unsure), students probably have insufficient insight to actually know and are guessing. Respondents have admitted that they had not previously thought about librarians in the context of the questions asked.

Outreach Programs and Library Services

While this study showed differences between those who did and did not participate in library lectures, even those who did were not highly sophisticated. Students are, to a great extent, unaware of educational requirements and capabilities of librarians as well as of traditional reference services and innovative outreach programs designed to further the role of librarians in the educational process. The effectiveness of publicity for such services and programs is questionable when promotion and advertisement are not making an impact on many full-time students. Alternatives and reinforcements merit examination and should incorporate insights from subject areas such as business administration, advertising, and marketing.

At the same time, public service librarians need expertise in the areas of psychology, sociology, education, interpersonal relations, and non-verbal communication. Programs not confined to small group instruction should be devised to reach large numbers of potential users, alter misperceptions, increase student/librarian contact, and promote a learning environment. Acquiring the necessary expertise for these services and programs is not the sole responsibility of individual librarians or library programs. Input, direction, and research should also come from library schools and professional library organizations, state, regional, and national. The organizations should be actively involved in promotional and educational techniques to raise the level of awareness in library users, current and potential.

\section{Recognition of Professional Librarians}

Many students, not just nonusers, do not fully utilize the services, knowledge, and expertise provided by librarians. Students explained their reasons for this in various ways. One major complaint was that librarians are unavailable or unrecognizable, partially due to lack of identification through use of name tags or plates, and partially be- 
cause librarians are often alienated from the student populace by adherence to administrative duties and little close contact with students except at the reference desk. Many students have become acclimated not to expect librarians to be available. Some felt that only students staff service desks, and many thought that anyone staffing a desk is a librarian.

Librarians need to emphasize their subject expertise and the reasons why students should differentiate among library staff. Service desks staffed by professionals should be clearly marked and apparent. Outreach programs should promote and instruct about not only library collections and research methodologies but also the role and abilities of librarians as educators.

\section{Interpersonal Relations with Students}

Research is needed to discover whether, and how much, interpersonal communication between librarian and student is affected by student perceptions. The objective is to make students willing to approach librarians, verbalize their needs, and return for further assistance when necessary.

Many students wanted librarians available both at a central desk and also in other areas of the library to give assistance at point of need. They usually wanted assistance on an individual basis and thought a desk hindered this. Contrary to replies (70.1 percent, never; 20.1 percent, sometimes), the reference desk was perceived as a barrier. To save time and minimize frustrations, the librarian, it was felt, should leave the desk to assist. In this way the librarian is seen to exhibit more genuine interest, is more attentive to student needs, and is better able to more effectively demonstrate the use of tools. Questions are then regarded with importance rather than annoyance.

The librarian not seated at a desk is less likely to be distracted. As one stu- dent commented, "When sitting behind a desk the librarian is often distracted by the phone, other parties, and assorted items on the desk, in addition to his or her own personal work." Statements pertaining to the unwillingness to disturb or bother a busy librarian were numerous. A common complaint was: "I hate to feel I'm putting someone out if that person is sitting behind a desk and is obviously busy."

Preoccupied, rude, inconsiderate, and discourteous service were common complaints causing resentment toward those working in libraries. Most of these were directed at personnel who did not voluntarily leave the desk to assist. Students preferred informality and attentiveness, wanted the librarian's complete attention so that their request would be fully understood and the research sources adequately explained, did not want to appear "stupid" or "dumb" in front of others, and were often embarrassed by their ignorance or lack of knowledge about the library. Responses, therefore, do suggest that many students desire closer personal contact and dislike it if the librarian is reluctant to leave a service desk for assistance.

\section{Image of the Preoccupied Librarian}

All activities and work carried out at the reference desk that might distract the librarian from giving full attention to reference requests or keep the patron from requesting assistance need examination and modification. As Swope and Katzer suggest,

Library administrators must recognize the necessity for circulating the library staff among users. A librarian cannot afford to be chained to a reference or information desk. If he is required to file a certain number of catalog cards, prepare book orders, or check invoices while manning the desk, he will never be able to change the image of the preoccupied librarian. ${ }^{8}$

This image of the preoccupied librarian 
is counter to the purpose of reference service and instructional outreach programs. The objective is to encourage, not discourage, students to seek professional assistance. Professional librarians should be available to receive and encourage in-depth reference questions. When clerical and student assistants are given simple reference requests, every precaution should be taken so that they do not further damage the image of academic librarianship, convert users into nonusers, or inhibit the willingness of users to seek assistance.

\section{Courteous or Discourteous Service}

Responses indicated that service desk personnel, including those at the reference desk, may belittle and intimidate users. This is especially true of a student asking for assistance a second time from the same individual. It seems that library personnel reinforce a self-image of inadequacy or ignorance. Students appreciate being encouraged to return for further assistance if needed. If the librarian periodically checks on students to see if they require further assistance perhaps those individuals will not be hesitant to approach a service desk the next time.

Generally students assumed that all reference assistance given is either good or bad depending on the past assistance they have received. For example, if a student was treated discourteously once, that student either assumes that everyone is treated in such a manner or completely avoids the offending staff member.

But if given competent, extensive service by a friendly, polite librarian, the student assumes that this is a standard policy. Even though a majority of students felt that reference service was competent and librarians friendly and helpful, the few who have had bad experiences project such experiences, and the reflection is adverse to the image that librarians want to convey. It is in- teresting to note that students suggested certain traits which they appreciated in a librarian. These included, among others, friendliness and politeness.

The question of courtesy or discourtesy warrants further research. What is considered discourtesy, and why, needs determination. In some cases, frustration might be caused by the fact that librarians, for various reasons, are unwilling to retrieve a specific book or information or that students are directed to look up a call number or check the card catalog for a specific book.

Awareness of student perceptions of librarians should affect scheduling during peak time periods, location of professional personnel at strategic service points, functions performed by librarians staffing service desks, and interpersonal relations. Librarians must try to prevent misunderstandings from arising. Several students, for example, commented: "What few times I have sought assistance and did locate someone, that person knew less about the library than I-and I know very little."

\section{Qualifications of THE Study}

As this university is primarily undergraduate oriented, no attempts were made to systemically discern the perceptions of graduate or special students. Generalizations cannot be made about students in this or other states or, for that matter, on this campus beyond the categories already presented. The researchers cannot generalize about parttime students. Still this study makes a beginning in an area in need of research and illustrates the value of survey instruments being tested for reliability and validity. Future studies can work with a set of hypotheses, ascertain why students hold particular perceptions or impressions, and experiment with methods to increase return rates.

The status factors, discussed above in the section on results, lack statistical documentation, as factor analysis was 
not applied. However, results of the analysis of variance demonstrate that the response pattern among the three research questions did not differ signifcantly and, therefore, lends support to their grouping as a single factor defining status.

Hopefully, the researchers have taken necessary precautions to insure that their findings did not come from a selfselected group. An initial impression might be that the survey results represent a biased sample in that library users were more likely to return questionnaires. However, fifty-four (14.9 per- cent) returned questionnaires came from students who did not use the library at all. There were sixty-seven responses (18.5 percent) from students who used the library only for social, study-hall, and reserve reading purposes. One reason for participation of these students might be that they think it is important for librarians to do research on libraries and their users. Future studies must further persuade nonusers that although they are not currently utilizing the library, librarians still benefit from their comments.

\section{REFERENCES}

1. Lawrence E. Leonard, Joan M. Maier, and Richard M. Dougherty, "Library User Attitude Survey," Centralized Book Processing (Metuchen, N.J.: Scarecrow, 1969), p.21143. Samuel H. Cameron and Karlyn W. Messinger, "Face the Faculty: Prevalent Attitudes Regarding Librarian-Faculty Relationships," Pennsylvania Library Association Bulletin 30:23-26 (March 1975) and 30:4851 (May 1975).

2. Maurice B. Line, "Student Attitudes to the University Library: A Survey at Southampton University," Journal of Documentation 19:100-17 (Sept. 1963).

3. Connie F. Evrand and Charles C. Waddington, "The Undergraduate Survey: Its Role in Changing Patterns of Reference Service," Drexel Library Quarterly 7:351-56 (JulyOct. 1971).
4. Mary Jane Swope and Jeffrey Katzer, "The Silent Majority: Why Don't They Ask Questions?" RQ 12:161-66 (Winter 1972).

5. John Lubans, Jr., "A Survey of the NonUsers of a Technological University Library," in International Association of Technological University Libraries, Educating the Library User; Proceedings of the Fourth Triennial Meeting, 1970, edited by C. M. Lincoln (Loughborough: Loughborough Univ. of Technology Library, 1970), p.J-4.

6. A bibliography based on a literature search has been prepared by the authors and can be supplied on request.

7. Line, "Student Attitudes to the University Library," p.116-17.

8. Swope and Katzer, "The Silent Majority: Why Don't They Ask Questions?" p.164-65. 